\title{
A oficina narrativa da poesia na escrita de José Craveirinha
}

\author{
Ana Mafalda Leite
}

Universidade de Lisboa

RESUMO: O PRESENTE ARTIGO BUSCA DESVELAR O VÍNCULO ENTRE A ESCRITA NARRATIVA E A ESCRITA POÉTICA DO MOÇAMBICANO JOSÉ CRAVEIRINHA (1922-2003), MOSTRANDO QUE, TAL COMO SEUS POEMAS POSSUEM UMA FORTE CARGA NARRATIVA, SEUS CONTOS E CRÓNICAS APRESENTAM TAMBÉM UMA VERTENTE POÉTICA FUNDAMENTAL, MARCADA PELAS POÉTICAS ORAIS DO SUL DE MOÇAMBIQUE, AO MESMO TEMPO QUE PELO REGISTRO CULTO.

ABSTRACT: THIS ARTICLE AIMS TO REVEAL THE CONNECTIONS BETWEEN THE POETRY AND THE FICTION OF THE MOZAMBICAN WRITER JOSÉ CRAVEIRINHA, ARGUING THAT, AS MUCH AS HIS POEMS PRESENT A STRONG NARRATIVE TRACE, HIS SHORT STORIES AND CHRONICLES ALSO SHOW RELEVANT POETIC PATTERNS MARKED BY THE ORAL POETICS OF THE SOUTH OF MOZAMBIQUE AND, AT THE SAME TIME, BY THE PRESTIGE VARIETY OF THE PORTUGUESE LANGUAGE AND CULTURE.

PALAVRAS-CHAVE: POESIA E NARRATIVA - LITERATURA MOÇAMBICANA - JOSÉ CRAVEIRINHA - ORALIDADE E LITERATURA KEY-WORDS: POETRY AND FICTION - MOZAMBICAN LITERATURE - JOSÉ CRAVEIRINHA 
publicação de Hamina e outros contos, de José Craveirinha (1997), reúne um conjunto de catorze contos e vem acompanhada de uma nota de apresentação do historiador António Sopa, que nos explica que todos estes contos foram publicados no semanário O Brado Africano, em 1955, ou pouco antes dessa data, com excepção de dois deles, publicados no jornal Tribuna, na década de 1960, nomeadamente Hamina far hara-quiri (1963) e Carta (1964). Somos ainda informados da existência de dois outros originais perdidos, uma novela, intitulada Magonde, extraviada nas mãos de um jornalista amigo, e um outro caderno de contos, desaparecido numa rusga da Pide.

A edição dos contos junta ainda um pórtico da autoria do próprio Craveirinha, que situa e explica a razão desses textos:

Era um tempo de outros tempos. Um tempo antigo. Quando não existiam presunções balofas. $\mathrm{O}$ que tinha de ser feito fazia-se. O exercício de escrita determinava um acto, uma vivência, um empenho em fazer agindo em função da palavra. E cada palavra reproduzia um lema. E o ideal. [...]

Literatura? Desenhismo? Menos sim, mais não. Talvez unicamente experiência de estar vivo. E realizando algo. Algo tangível. Algo não estagnado. Algo com destino. Algo circulando de mão em mão.

Uma época com duendes. Xipocués temíveis que era preciso iludir. Como? Fazendo. Nomes? Um Nuno Abranches de Sousa. Um Fonseca Amaral. Uma Noémia de Sousa. Um Luís Polanah. Um Sharfudine Khan. Um António Bronze. Uma Maria da Luz. Um Rui Nogar. Um Aníbal Aleluia e um tal José Craveirinha.

Cada um com um quinhão da tarefa de todos. E frequentes vezes um telefonema aflitivo: - Zé, “esgalha” aí qualquer coisa para fechar a página. É urgente por causa da hora de impressão. E não te esqueças dos tipos da censura.

E o tal Zé "esgalhava" essa "qualquer coisa". Um texto rascunhado sobre o joelho. À pressa e com o pensamento nos tais implacáveis duendes desse tempo [...] (CRAVEIRINHA, 1997: 15-16) 
Dois anos depois, o Centro Cultural Português de Maputo faz editar Contacto e outras crónicas, que agrupa uma muito breve amostragem de cerca de duas dezenas das crónicas jornalísticas de Craveirinha, também com uma apresentação de António Sopa. Com uma coluna regular - Contacto - em O Brado Africano na década de 1940, o poeta transita para o Notícias, no início da década de 1950, com uma coluna com o mesmo título. São referidas várias outras colaborações e colunas, em outros jornais, ao longo das décadas de 1960 e 1970.

A maioria das crónicas publicadas nessa obra enquadra-se nesse âmbito cronológico, que vai da década de 1950 a 1970, como se constata pela indicação do jornal e da datação no índice.

Interessa-nos a delimitação cronológica porque o assunto deste artigo visa demonstrar, ou antes, fazer reflectir, certa problemática que os textos narrativos de Craveirinha levantam ao analista da sua poesia.

A questão foi-se-me colocando quando fiz a primeira leitura dos contos; recentemente, ao fazer a segunda leitura, já com uma atenção analítica diferente, comecei, de novo, a rever, fragmentariamente, mas já de diversos modos, muitos dos poemas de Xigubo e de Karingana wa Karingana, em várias daquelas narrativas. Em relação às crónicas, e lidando apenas com o limitado corpus editado, apercebi-me de que havia também algumas relações a problematizar com a poesia.

Um dos aspectos que eu salientei, e desenvolvi longamente, no meu estudo sobre a poética de José Craveirinha, foi o tópico da passagem da poeticidade à narrática, caracterizando na poesia do autor os títulos, as marcas narrativas, a existência de personagens, a organização espácio-temporal, entre outros aspectos, bem como o vínculo à poesia oral dessa faceta narrativa da poesia craveirínhica.

Em outro estudo meu sobre a actual narrativa moçambicana (LEITE, 2003) mostrei que a grande diferença em relação ao período colonial se manifesta, nos dias de hoje, pelo maior número de prosadores em relação a poetas, e que se podia pensar numa tradição de escrita poética, formulada na encruzilhada entre o cosmopolitismo e a nativização, de que os expoentes seriam Rui Knopfli e José Craveirinha, salientando que este último consagrou uma escrita proteiforme, travejada pelas poéticas orais do sul de Moçambique, ao mesmo tempo que seduzida pelo registo culto. Dessa combinatória resultou, 
muitas das vezes, uma escrita em que o ritmo narrativo predomina sobre o registo fragmentário da lírica: Karingana wa Karingana " "era uma vez", como tão sedutoramente evoca o título do seu segundo livro.

Evidenciei ainda que o achamento de tal vertente poético-narrativa, cujos fundamentos se alicerçam nas práticas orais do sul de Moçambique ${ }^{2}$, que o poeta conheceu e aprofundou, contribuiu, pensamos, para o alargamento e a localização de uma escrita, mergulhada, como a parte invisível do iceberg, nesse território cultural/oral, dinamizador e fundacional da futura-actual escrita narrativa moçambicana.

Assim, a oscilação, ou indefinição, das estruturas poético-narrativas, a dominante de uma voz colectiva e laudatória, entre muitos outros aspectos, explicam esta recorrência à inscrição de modelos orais na poesia moçambicana, que se revela, pensamos, um dos caminhos mais aliciantes, em via de instituição, na prática narrativa pós-colonial.

Considerei que, apesar de uma esporádica tradição anterior ${ }^{3}$, os novos autores de ficção, ao recriarem a sua enunciação no terreno das poéticas orais, recorrem também ao modelo iniciado pela poesia narrativa de José Craveirinha, ao Karingana wa Karingana, iniciático título do poeta, e fórmula de abertura da narração oral, repondo estes novos narradores, na sua escrita, uma arte griótica, o maravilhoso do era uma vez, contando a forma como se conta, na sua terra, ao encenar tais estratégias narrativas.

Esse ponto de vista vem agora a confirmar-se uma vez mais, após estas releituras dos textos narrativos do poeta José Craveirinha, dos contos e das crónicas. E porquê? Primeiro, porque me parece haver um vínculo íntimo

${ }^{1}$ Título do segundo livro de José Craveirinha, publicado em 1974.

${ }^{2}$ No que respeita à oratura moçambicana, como já referi mais atrás, Henri Junod, na obra Usos e costumes dos bantos (1974: 161), refere três tipos diferentes de género ("estilo") no folclore tsonga: a poesia didáctica e sentenciosa que se encontra nos provérbios, máximas e enigmas, a poesia narrativa nos contos de todos os géneros e a poesia lírica nos cantos.

${ }^{3}$ As publicações mais significativas no domínio da ficção no período colonial são os livros de contos de João Dias, Godido e outros contos, em 1950, de Luís Bernardo Honwana, Nós matámos o cão tinhoso, em 1964, e o pequeno romance Portagem, de Orlando Mendes, em 1965. Todos esses livros nos narram histórias que documentam a opressão do colonizado, e se situam no contexto da situação de discriminação racial e económica que então se vivia na colónia portuguesa de Moçambique. 
entre a escrita narrativa e a escrita poética do autor. Tal como os poemas têm uma forte carga narrativa, os contos e crónicas têm também uma vertente poética fundamental.

E uma outra questão se me coloca: qual a conexão entre os textos narrativos, os contos, as crónicas e os poemas? Ou, ainda, qual a génese, sequência cronológica entre uns e outros? Foram escritos em simultâneo, antes, ou depois, os contos, as crónicas ou os poemas?

Lamento já não poder dialogar com o poeta sobre este assunto, que certamente me seria iluminador para resolver alguns destes aspectos; todavia, a personalidade de Craveirinha, marcada por uma sábia ironia e uma sempre, exagerada, humilde postura face à sua escrita, poderia eventualmente não me esclarecer muito. Explico-me melhor. Relendo de novo o seu pórtico aos contos, ou lembrando-me da forma como me foi feita a dedicatória no livro, ou os seus comentários, na época, sobre a publicação desses contos, verifico que Craveirinha considerava essa escrita narrativa um acto não suficientemente depurado, o que justifica um pouco esse seu distanciamento crítico relativamente aos contos. Mas a justificativa de serem feitos "sobre o joelho" parece-me não se aplicar a todos eles, uma vez que grande parte dos textos é acompanhada por desenhos e linóleos que os tematizam.

Ou feito à última da hora, escrita e desenho, ou, outras vezes, tanto a escrita, como as ilustrações, cumpriram um tempo de criação. $\mathrm{Na}$ realidade, julgo que nem todos os contos, tal como os desenhos, resultam de um esboço de urgência momentânea, porque alguns deles revelam muita qualidade e exercício estilístico, mesmo oficinal.

No caso das crónicas, a escrita será eventualmente mais breve, menos elaborada, exercendo a sua funcionalidade crítica e temporal. Mas, mesmo nas crónicas, há momentos de irrupção da palavra poética e de quebra da linearidade do discurso jornalístico.

As hipóteses de trabalho que vou adiantar neste artigo resultam de dois eventuais pressupostos, ou seja, alguns poemas de José Craveirinha são uma outra versão dos contos, recriam temas de algumas crónicas; muitos dos poemas de Xigubo (1964) e de Karingana wa Karingana (1974) teriam sido feitos em simultâneo aos contos, à escrita das crónicas, partilhando de temas similares, preocupações sociais, e do universo de ideias que povoava a mente do escritor-jornalista. A época e o quadro cronológico de produção são sensivelmente os 
mesmos, e conhecendo-se a prática oficinal de múltiplas versões dos seus poemas, não custa a crer que possa ter escrito paralelamente os contos, crónicas e poemas.

Isto não exclui, talvez, uma outra hipótese, de pesquisa genealógica dos poemas, que considero muito produtiva e provável, e que orienta este artigo, a de que, em alguns casos, a primeira versão, remota ou quase simultânea, de certos poemas tenha sido, mesmo, a versão narrativa.

Repare-se que essa hipótese de trabalho assenta, de momento, em três elementos, resultantes da minha análise.

A primeira, de que as crónicas, imitando a técnica pictural do esboço, oferecem temas e sugestões de trabalhos para poemas que virão a surgir. Comecemos pelos títulos, e repare-se no título de uma das crónicas recolhidas por António Sopa: “Três apontamentos sobre um poema que nunca será escrito" (CRAVEIRINHA, 1999: 29). A escrita em prosa desta crónica, organizada em três partes, como muitos dos poemas de Karingana wa Karingana, resume, talvez, o que pretendo adiantar: o poema (futuro) vive de esboços anteriores - apontamentos em prosa - esboços, anotações, que, posteriormente, podem vir a ser transformados em poesia.

Este tipo de procedimento reflecte-se, por seu turno, na obra poética. No livro Karingana wa Karingana encontramos um poema com o título "Suelto" (p. 25). O suelto é um pequeno comentário jornalístico sobre assuntos do dia, uma croniqueta. Verificamos, então, que tal como o espaço de escrita da crónica é lugar de reflexão sobre um possível futuro poema, o poema recupera essa herança discursiva do anterior registo da crónica.

Dois casos relativamente flagrantes no conjunto de crónicas editadas são a crónica "Despedida de Daíco" (Voz de Moçambique, 1970) e "Mensagem para um ex-algarvio: meu pai" (Notícias da Beira, 1973). Vamos encontrar em Karingana wa Karingana dois poemas resultantes destes mesmos motivos, "Dó sustenido por Daíco" e "Ao meu belo pai ex-emigrante", sendo dois textos longos e com forte carga narrativa.

Na crónica "Mensagem para um ex-algarvio: meu pai", lê-se:

Quando resolveste vir para África e deixaste a tua Aljezur, nem Tu sabes o que viria a acontecer. Pois isto agora está muito diferente. (...) No teu tempo, fazer uma casinha correspondia a uma série de sacrifícios durante anos e anos e 
muito trabalho. [...] Pai: Foste um sonhador. Vieste pobre e morreste pobre. Hoje isto já não se usa. [...] Meu pai: Quando deixaste o Algarve e vieste para Moçambique, não era assim! (CRAVEIRINHA, 1973: 75-77).

A prática da interlocução e do diálogo que surge já na crónica é retomada no poema. A evocação da figura paternal vem a ganhar no poema dimensões biográficas muito mais precisas e intencionais.

$[\ldots]$

Oh, Pai:

Juro que em mim ficaram laivos

do luso-arábico Aljezur da tua infância

mas amar por amor só amo

e somente posso e devo amar esta minha bela e única nação do

Mundo

onde minha Mãe nasceu e me gerou

e contigo comungou a terra, meu Pai.

$\mathrm{E}$ onde ibéricas heranças de fados e broas

se africanizaram para a eternidade nas minhas veias

e teu sangue se moçambicanizou nos torrões

de sepultura de velho emigrante numa cama de hospital

colono tão pobre como desembarcaste em África

meu belo Pai ex-português. (p. 108)

Em relação à crónica sobre Daíco, verificamos que a intenção elegíaca e celebratória, evidente nesse breve ensaio cronístico, acabará por não se restringir à episódica publicação em jornal.

Daíco era mais do que um tocador de viola de um cabaré qualquer da periferia do cais: era um deus da sua viola e a sua viola era o deus de toda uma geração de homens que já acreditaram em serenatas ao luar nas ruas da cidade. [...] Daíco não morreu nem morre nunca. Está vivo. E vai continuar a tocar maravilhosamente a sua viola em cada história que o cancioneiro da terra irá criando. Daíco há quarenta e quatro anos que é uma lenda em Moçambique. (CRAVEIRINHA, 1970: 54) 
Com efeito, o poema, "Dó sustenido por Daíco", dedicado a Noémia de Sousa (Carol), e organizado em forma de carta que informa da notícia da morte do exímio tocador, retomará numa longa e bela elegia a vida deste personagem da vida cultural moçambicana.

$[\ldots]$

Pois é, Carol

vou terminar esta carta enviando-a sem via

sobre a amnistia de quarenta e tal anos de exílio

do Daíco dentro de Lourenço Marques a tocar bacilos

mas não estejas pensativa nem triste onde quer que estejas

que o Daíco executa agora resvés no coração da pátria

de improviso a resistência da última posição

no corpo inteiro em contracanto. (p. 113)

As duas outras hipóteses de trabalho, a segunda e terceira, que adianto exploratoriamente neste ensaio, têm a ver com os contos. Nestes, a relação genética com os poemas estabelece-se por meio não só do aproveitamento de temas, mas ainda de ritmos, de construções frásicas, de marcas estilísticas, que se tornam mais visíveis. Esta a segunda proposta de trabalho.

A terceira é a de que alguns contos fazem mesmo transição para os poemas. São uma escrita similar a uma prosa poética, em que o enredo é muitíssimo fragmentário, e organizam-se em três ou quatro tempos, explorando já as potencialidades da página em branco. A presença do narrador oscila entre uma enunciação do sujeito poético. Podem não ter ligação temática muito evidente com nenhum poema futuro, ou podem tê-la também, mas são como um pequeno laboratório oficinal, uma vez que revelam como a escrita narrativa está já em transição para a poética. Neste caso consideramos, a título de exemplo, os contos "Carta" e "Fantasia em quatro actos".

No conto "Fantasia em quatro actos", a cena descrita da dança e do som dos tambores, é como se estivesse organizada em quatro estrofes numeradas e separadas por momentos de evocação diversos. Também nesse conto encontramos elementos temáticos e ritmos que preparam poemas de Karingana wa Karingana, como o poema "Deixa-me ser tambor", ou o poema "História 
do magaíza Madevo", cujo nome aparece simultaneamente no conto e no poema, caso que testamos em outros contos, crónicas e poemas.

Aliás, percebe-se que muitos dos nomes das personagens transladam dos contos para os poemas, sendo frequente o uso dos mesmos nomes próprios nos contos e nos poemas, mas com diferente representação profissional. Não deixa de ser curioso, a esse respeito, o emprego do nome "Sonto" em personagens crianças nos contos, como por exemplo em "História de Sonto: o menino dos jacarés". Como se sabe, este era o nome como o poeta José Craveirinha era tratado em criança; a projecção biográfica, que se tornará relevante em muitos poemas de Karingana wa Karingana, aparece já embrionária nos contos, com o emprego da sua identidade ficcionada.

Com efeito, nos poemas, as personagens têm normalmente nome próprio, ou nome familiar, e trata-se de figuras referenciáveis, isto é, algumas pertencem ao círculo da família, outras são amigos. Em relação aos amigos, verificamos mais atrás a evocação do pai e de Noémia de Sousa/“Carol” e, no mesmo poema, Daíco, a figura artística suburbana. Nesses casos, os textos/ elegias adoptam o registo lírico-dramático da interpelação, para se tornarem narrativos e relatarem os principais episódios da vida do pai e do músico.

Mas voltemos ao conto "Fantasia em quatro actos":

É Deus de todos o Ritmo. Ghiculo, txacla, estão contentes no salão mais belo do mundo e os sons voam como asas de xitotonguana. [...]

Deus-Madhevo tomou conta do mulato Jeremias, afivelou-lhe a sua máscara de rictus fixo de riso e de longos cabelos brancos e crespos puxados para trás. [...] Jeremias Siqueti tem Deus-Madhevo dentro de si e o seu espírito ri... ri... na máscara carregada de impassibilidade.

Jeremias é um pedaço de ritmo sarcástico que zomba do velho mundo dos homens $[\ldots]$

Enquanto os tambores se juntam na festa dos sons como espíritos do bem e do mal, na floresta das almas tomadas de xicuembo, Jeremias Siqueti dança com Deus-Madhevo dentro do seu corpo e a máscara (Fantasia em quatro actos, p. 61)

Ghiculo e txacla são nomes de tambores, e a frase inicial "É Deus de todos o ritmo" mostra como é importante o som do tambor e o ritmo por ele desencadeado. No princípio não era o verbo..., antes o ritmo. Esta junção 
entre divindade e ritmo, entre som do tambor e poder, exaltação, vai ser retrabalhada no poema "Quero ser tambor", de Karingana wa Karingana.

\author{
Tambor está velho de gritar \\ ó velho Deus dos homens \\ deixa-me ser tambor \\ só tambor gritando na noite quente dos trópicos. (p.123)
}

Aí o poeta reclama-se do som ancestral dos tambores, tenta totemicamente incorporar em si ("Quero ser tambor") o valor simbólico-ritual dos antepassados e da poesia oral. Tal como no poema "Manifesto", do primeiro livro, Xigubo, o corpo hiperbolizado é simultaneamente sacrificial, redentor e totémico, corpo-mapa de África, contudo, em “Quero ser tambor” já não é o corpo, mas a voz que ganha essa capacidade colectiva transfiguradora e mágica.

No conto "Carta", título que virá a surgir em muitos dos poemas de Karingana wa Karingana ("Carta para uma Maria João", "Carta para a mãe dos meus filhos”), não há enredo, antes reflexão, congeminação sobre a vida, a mulher, a rebeldia, o acto criador e a natureza. Não se intui nenhuma fábula, nota-se a assunção de uma forte sensualidade (presente nos poemas futuros) e a consciência firme de uma oficina de escrita, que oscila ente a prosa e a poesia: "E não sobram asas que não as ganhe no seu corpo dia a dia o poeta, feliz ainda na humildade do artesão no êxtase da técnica das formas perfeitas, construindo na matemática dos dedos as próprias obras de arte". O conto "Carta" não cumpre o seu título, podia ser uma mistura entre crónica e poema, e oferecenos, metapoeticamente, uma apreciação sobre o labor poético.

Levava agitados os pendões da sua rebeldia. Eram os cabelos soltos de uma boca de lábios famintos de cosmovisões delirantes de posse na tarde morna, invocação de uma beleza - delito de ser mulher. Amavam-na: o espaço à justa no ar em que o seu corpo ondulante se movia; a regra de jogo da adulação máscula dos olhos no encantamento da sensualidade; o impacto panfletário; os estáticos seres aparvoados: ÁRVORES - vidas vegetais com raízes fincadas no seu lar de torrões $(. .$.

Calo em mim o resto da verdade inteira que se não aprende mas zumbe zumbe ao norte do tempo como se quisesse a fantasmagoria de um cutelo libertino 
de gume cor de madrugada, tangendo nas ancas de uma viola os sons virilizantes do pão da própria harmonia. E o galo é uma ave que já não atinge o céu voando mas comprometido no alerta do seu canto antes do holocausto. E não sobram asas que não as ganhe no seu corpo dia a dia o poeta, feliz ainda na humildade do artesão no êxtase da técnica das formas perfeitas, construindo na matemática dos dedos as próprias obras de arte. (p. 29-30)

Vou dar outros exemplos sobre essa teia de relações entre contos e poemas. Começarei pelos títulos de três outros contos, "Chigubo", "Mamana Fanisse", "Natal", designações que encontramos também atribuídas a poemas incluídos nos dois primeiros livros de poesia de Craveirinha. O título do conto "Chigubo" é, inclusive, além de título de poema, o título do livro inaugural do autor. Leia-se um fragmento do conto:

O sol vazava calor. O sol e a pele esticada dos tambores. Chigubo! Chigubo! O som escorria na tarde morna com o seu poder de mutóvana. O som e o suor das caras dos homens no meio do batuque. [...]

O chigubo soa. [...]

A terra treme, a areia salta, o suor escorre, as peles brilham e a voz do chigubo soa. São dois e o sangue à volta é do chigubo. Os pés batem e o ritmo é bangue, o sangue esquece e só a dança fica, é sura e céu.

A terra treme, os pés entram na terra; pés e terra, terra e pés, pés e terra. Suor e ritmo na atmosfera revolvida de sons até ao regresso milenar, a voz do chigubo ao condão dos paus chama e é bangue. (p. 37)

Leia-se agora um fragmento do poema:
Tantã!
E os negros dançam o ritmo da Lua Nova
Rangem os dentes na volúpia do xigubo
E provam o aço ardente das catanas ferozes
$\mathrm{Na}$ carne sangrenta da micaia grande.

\footnotetext{
${ }^{4}$ A grafia inicial da palavra nos livros do autor é com $c h$; na segunda edição surge $\operatorname{com} x$.
} 
$\mathrm{E}$ as vozes rasgam o silêncio da terra

Enquanto os pés batem

Enquanto os tambores batem

E enquanto a planície vibra os ecos milenários

Aqui outra vez os homens desta terra

Dançam as danças do tempo da guerra

Das velhas tribos juntas na margem do rio. (p. 10)

Semelhante recuperação de processos rítmicos, além de temáticos, pelo desenvolvimento, agora, do motivo da prostituição, é visível na leitura comparada entre o conto "Mamana Fanisse" e o poema de Karingana wa Karingana, "História das lagoas":

Fanisse trabalhava a terra, curvada, os grandes seios suspensos como papaias [...] Mamana negra cavava e a cada golpe do chicomo a terra escura abria-se em largas feridas generosas (p. 75)

Todo o suor derramado durante dias e dias, de manhã à noite, a espera ansiosa, chove-não-chove, cresce-não-cresce e o Sonto nas costas, a dormir ou a mamar com a boca ávida colada ao seio [...] Na noite das Lagoas vê-se uma sombra à porta de uma barraca: Mamana Fanisse voltou [...] Matolo morreu na mina e Mamana deixou chicomo e está na vida. (p. 79)

E leia-se agora o poema "História das lagoas":

Vem não vem marinheiro / coitado filho de Leta / coitada mãe de sua mãe / coitada janela acesa na barraca das Lagoas / coitados nós todos filhos / da coitada Leta Conceição! (p. 75)

Também ao lermos o conto "Hamina” reparamos que certas marcas estilísticas e retóricas presentes nessa narrativa, inclusive o ritmo, se transportam para a elaboração de alguns poemas. Este fragmento do conto é revelador:

Quem plantou aquele tabaco? Quem regou aquele tabaco? Quem apanhou aquele tabaco? Ninguém. 
Quem fez Hamina? Quem ensinou Hamina? Quem mandou Hamina? Quem chupou Hamina? Foi saraveja. Foi cigarro. Foi uísque de chá. Foi vinho de água. (p. 21-22)

A interrogação é ritmada, provocando, na escrita narrativa, um crescendo anafórico, característico da poesia; os paralelismos de construção frásica lembram versos. E nos versos do livro Xigubo lemos, no poema "Ode a uma carga perdida num barco incendiado chamado Save", similar construção dialógica e anafórica:

Quem foi que gritou? Foi a carga

Quem foi que ardeu? Foi a carga

Quem foi que explodiu? Foi a carga

Quem foi que desapareceu? Foi a carga. (p. 27)

Um outro conto, "Natal", por exemplo, já contém elementos narrativos e fabulares que vamos encontrar no poema "Fábula", de Karingana wa Karingana:

Um búzio grande soprava na alma de Maguébe as ânsias de um menino sem um balão sequer na mão escura, um reles balão encarnado para ele assoprar, o balão inchando como um sapo enorme. (p. 91)

Senão, observemos o desenvolvimento do poema "Fábula", por exemplo, que retoma, talvez ainda que indirectamente, a fábula de La Fontaine "A rã e o boi", na qual a rã incha até rebentar com a ambição de querer ser tão grande como o boi. No conto, verificamos a indicação de sapo por rã, estando mais explícita a referência intertextual. Apesar de ser a moral um pouco diferente no poema, existe sem dúvida uma semelhança temática. Aqui a implícita fábula é metaforicamente substituída pelo menino gordo e pelo menino magro, e a referência à ausência do "balão" no conto anteriormente referido é aqui retrabalhada numa moral crítica, ajustada ao desnivelamento social, representada no universo infantil, de forma chocante e antitética. O par gordo/magro a fazer juz ao par balão/balõezinhos, e o verbo "assoprar" ritmando um crescendo de arrogância e poder: 
Menino gordo comprou um balão

e assoprou

assoprou com força o balão amarelo.

Menino gordo assoprou

assoprou

assoprou

o balão inchou

inchou

e rebentou!

Meninos magros apanharam os restos

e fizeram balõezinhos. (p. 18)

O mesmo conto, "Natal", pode ser visto ainda como uma proto-escrita de um outro poema, "Natal", de Karingana wa Karingana. O início do conto relata-nos o percurso de um menino, vendedor de espargos, que não tem nada e olha o fausto das montras no dia de Natal:

A cidade acordou em festa.

Natal! Natal!

A Baixa encheu-se de gente. Nas lojas os brinquedos atraíam os pais com as crianças pela mão. Maguébe o negrinho, sobraçando seu monte de espargos, parou em frente de uma montra. Os olhos abriram-se gulosamente perante as maravilhas tão perto e tão longe dele, que aquilo tudo era um sonho boiando nas pupilas redondas e cheias de todas as fomes de África. Triciclos, motos, camiões, aviões e tantas coisas mais, feitiçaria misteriosa para Maguébe, estavam ali atrás do muro de vidro. (p. 91)

Esse mesmo tema é desenvolvido no poema com o mesmo título, e a presença da montra, fronteira de inacessibilidade entre o olhar exterior para o interior, marca o abismo entre a pobreza do menino dos subúrbios e a riqueza ostentatória da cidade. É Natal, altura de prendas, de fraternidade religiosa, mas essa mensagem de Natal não se cumpre em tempo colonial:

Roto e descalço

vai o garoto dos subúrbios 
de rua em rua

pelas montras da cidade

poema de Júlio a chorar

janelas de vidro do Natal

iluminadas a lâmpadas furta-cores

com meu irmão da Munhuana espreitando. (p. 152)

Também no conto "Mamana Fanisse" encontramos a referência ao poema de abertura do livro Karingana wa Karingana, retomando-se dos contos a prática narrativa, agora integrada na lírica:

Cocuana Sambeca já tem mais uma história para contar aos seus netos, as mãos estendidas para o lume duma fogueira de capim seco: Karingana wa Karingana? E as vozes respondendo: Karingana. (p. 79)

Leia-se a resultante em poema no livro Karingana wa Karingana:

Este jeito / de contar as nossas coisas / à maneira simples das profecias / - Karingana wa Karingana! - / é que faz o poeta sentir-se / gente / E nem / de outra forma se inventa / o que é propriedade dos poetas / nem em plena vida se transforma / a visão do que parece impossível / em sonho do que vai ser. // - Karingana! (p. 13)

São três as histórias que aparecem em Karingana wa Karingana: "História do magaízo Madevo" (p. 58), "História de amor" (p. 60) e "História das lagoas” (p. 75). O título, enquanto classificação de gênero, não significa o mesmo que conto, no entanto, são pequenas narrativas poéticas que relatam, no primeiro caso, a viagem de um trabalhador que parte para as minas da África do Sul; no segundo poema, tal como o título indica, trata-se de uma história de amor; no terceiro, da vida de uma prostituta.

A primeira história é a que contém o maior número de elementos narrativos, aliás, até porque trata de uma viagem e marca um circuito espacial e temporal muito referenciado. De qualquer forma, tanto a primeira como a terceira histórias poderiam ser repetidas e interminavelmente contadas. As 
suas personagens, que vêm nomeadas, funcionam como paradigma de outras mil histórias semelhantes.

O que podemos dizer é que esse processo é igualmente aplicável aos contos.

A oficina narrativa da poética de José Craveirinha parece ser uma teia em que as diferentes escritas se entrelaçam e comunicam, num diálogo de apuramento e de escrita em processo.

\section{Referências Bibliográficas}

CRAVEIRINHA, José. Contacto e outras crónicas. Maputo: Instituto Camões, 1999. Hamina e outros contos. Lisboa: Caminho, 1997.

JUNOD, Henrique A. Usos e costumes dos bantos. Maputo: Imprensa Nacional de Moçambique, 1974/1975. $2 \mathrm{v}$.

LEITE, Ana Mafalda. Literaturas africanas e formulações pós-coloniais. Lisboa: Colibri, 2003. 